\title{
Relations between feces, urine, milk and blood fatty acid contents in cattle
}

\begin{abstract}
The various fatty acids found in the circulation, cells and tissues of animals that have an important place in the feeding of animals are important components of cell membranes related to events that occur in a rich source of energy and cells. Since the fatty acids groups having important functions can not be synthesized by the mammalian cells, they must be taken from the outside of the body. Fatty acids detected in blood, feces, milk and urine can be an indicator to diagnose some metabolic disorders. This study was conducted to investigate the correlation between fecal matter, urine, milk and blood fatty acid contents in Holstein cows by multiple regression analysis.
\end{abstract}

As a result, milk, blood, stool and urine fatty acid contents were statistically significantly related to each other $(\mathrm{p}<0.01)$.

Keywords: fatty acid contents, cattle, relation
Volume 3 Issue 6 - 2018

\author{
Özgü Anitaș, Serap Göncü \\ Department of Animal Science, Agricultural Faculty, Cukurova \\ University, Turkey
}

\section{Correspondence: Serap Göncü, Department of Animal Science, Agricultural Faculty, Cukurova University, 01330 Adana, Turkey, Email serapgancu66@gmail.com}

Received: September 18, 2018 | Published: November 28, 2018

\section{Introduction}

Fatty acids and their metabolic products have important functions in the animal's body. These functions include being an active energy source, providing resistance to external factors, being the cornerstone of the cell and membrane, and acting as a precursor to hormone-like eicosanoic compounds such as prostaglandins, thromboxanes, and leukotrienes. In addition, hormone-like compounds play a role in the central nervous system, inflammatory diseases and other hormones in the immune system and in the regulation of blood pressure. ${ }^{1,2}$

Polyunsaturated fatty acids (PUFA) have been shown to be effective on many diseases in animal body metabolism. Lack of PUFAs indicates that major metabolic disorders such as chronor heart disease, imbalance in blood and lipid levels, high blood pressure, arthrosclerosis, thrombosis, heart failure, cancer, asthma, febrile diseases and arthritis have arisen..$^{3-5}$

Monocarboxylates (especially acetate, propionate and butyrate), termed short chain fatty acids, are the last products of anaerobic microbial fermentation of carbohydrates in the ruminant gastrointestinal tract. Monocarboxylates are absorbed through different parts of the gastrointestinal tract and produce significant amounts of energy in ruminant animals. It also plays a central role in metabolic communication between cellular metabolism and tissues. They are easily passed from the bowel to the blood and hepatic gluconeogenesis is transplanted into the body tissues to be used in lipogenesis and milk synthesis in peripheral tissues. In the investigations carried out it has been reported that the monocarboxylate carrier family in the plasma membrane of the cell is responsible for the transfer of short chain monocarboxylates. ${ }^{6}$ Despite the importance of short chain fatty acids (SCFA) as the main energy source in ruminant animals, the mechanism of SCFA transport and absorption is still not fully explored. In their study of Tagang et al., ${ }^{6}$ it is stated that monocarboxylate carrier proteins have two main functions, which are facilitating the absorption of SCFA in the gastrointestinal tract and regulating cell $\mathrm{pH}$ in skeletal muscles. It has been reported that these tasks are important in terms of physiological homeostasis, animal welfare and productivity.

Fatty acids were first described by Burr in the early 1930s. These authors have identified linoleic acid (C18: 2 n6) and alpha linolenic acid (C18: $3 \mathrm{n} 3)$, important fatty acids in pigs and rats, as essential essential fatty acids for growth, skin structural health and reproduction in their research. Since then, researchers have shown the importance of fatty acids, which are lipid mediator molecules, such as prostaglandins, prostacyclins, thromboxanes, leukotrienes, liposines, and resolvins, which affect cellular function.Fatty acids taken into the body are included in the phospholipids in cell membranes to determine the structural and functional properties of the cells. ${ }^{8}$ Animals use fatty acids (FA) to grow, to maintain a fertile lactation period, to have a healthy lifestyle, and to increase fertility. In mammals, since cells can not synthesize some fatty acid groups, they must be taken from the outside with feed. Fatty acids are hydrophobic or amphipathic molecules.It has the functions of forming structural components of cell membranes, synthesizing prostaglandins and attaching proteins to cell membranes.Fatty acids are also stored as intracellular triacylglycerides (TAG) in lipid droplets and provide a powerful source of energy when the body needs it. ${ }^{8}$

Severe negative energy balance in early lactation causes metabolic disturbances in dairy cows. ${ }^{9}$ During this period of negative energy balance, the body, fat and muscle proteins function to compensate for the energy deficit. ${ }^{10}$

The widespread mobilization of body reserves significantly increases the concentration of free fatty acids (FFA) in blood plasma in early lactation. Accordingly, FFA's liver uptake, oxidation of the FFA or conversion to very low density lipoproteins exceeds the capacity of the liver. ${ }^{9}$ This leads to the accumulation of triacylglycerol (TAG) in the liver, which increases the oxidation of ketone bodies and increases the incidence of ketosis and fatty liver, such as mastitis.

Animal welfare has an increasing prevalence and the lack of chronic stress in the animal is one of the preconditions for animal welfare. Especially in scientific research, when sampling for analysis, it is necessary to improve the environment for animals to survive stress and to treat them with the least stress.During the blood, saliva or urine collection, some manipulations of the animal are applied and these applications in free, moving animals are stressful to the practitioner and animal. For this reason, it is very important to have various health indicators in easily releasable samples of animals. In recent years, the bioindicator has been seen as a priority work in this way. 
The purpose of this study was to determine the fatty acids in urine, blood, milk and fecal samples taken from animals by Gas Chromatography and to determine the relationship between fatty acids and their importance for cattle breeding.

\section{Material method}

In this study, samples taken from holstein cows with healthy and similar characteristics grown in Cukurova University Faculty of Agriculture Rotating Capital Management, Dairy Cattle Research Unit were used. Experiemantl cows were fed with a total mixing ratio (TMR) of 60: 40 for the coarse feed ratio.

TMR is a mixture of corn silage, alfalfa, wheat straw and concentrate $(18 \%$ crude protein and $2650 \mathrm{kcal} /$ metabolic energy $(\mathrm{ME}) / \mathrm{kg}$ ), and is given at 07.00 and 16.00 in the morning.Experimental animals are provided with an automatic milking system at the central milking place twice a day for 12 hours. Experimental material Milk, blood, feces and urine samples were collected from Holstein cows and fatty acid analyzes were determined by Gas Chromatography in the laboratories of Fisheries Faculty of Cukurova University.Urine samples were obtained by manual stimulation of perineal regions of cows and stool specimens as described by Sankar and Archunan; ${ }^{11}$ Blood samples were obtained from Klemm et al. ${ }^{12}$ Milk samples were taken from the first milk that accumulated at the tip of the nipple after the milk was milked and the samples were transported to the analysis under proper conditions to preserve the cold chain. Blood samples were collected in the early morning vena jugularis

Samples were prepared by mixing $10 \mathrm{ml}$ aliquots of $10 \mathrm{ml}$ sodium citrate in a $30 \mathrm{ml}$ injection syringe, sealed with a teflon coated septum. The samples were rapidly frozen and stored at $-80^{\circ} \mathrm{C}$ for analysis by gas chromatography.

Bligh \& Dyer ${ }^{13}$ method was used for lipid extraction from animal samples. Methyl esters to be formed from the samples were prepared by transmetallation using $2 \mathrm{M} \mathrm{KOH}$ in methanol and n-hexane; $10 \mathrm{mg}$ of extracted oil was dissolved in $2 \mathrm{ml}$ of hexane, then $4 \mathrm{ml}$ of $2 \mathrm{M}$ methanolic $\mathrm{KOH}$ were added. The tube was then taken to the hexane layer for GC analysis after centrifugation at 4000rpm for 10 minutes, vortexing for 2 minutes to thoroughly mix the liquor at room temperature.
$20 \mathrm{ml}$ of the collected samples were sieved using filter paper (60$120 \mu \mathrm{m})$ and stored frozen at $-20^{\circ} \mathrm{C} .^{14}$

Samples were analyzed by GC Clarus 500 with an automatic sampler (Perkin Elmer, USA) equipped with a flame ionization detector and a silica capillary SGE column $(30 \mathrm{~m} \times 0.32 \mathrm{~mm}$, ID x $0.25 \mu \mathrm{m}, \mathrm{BP} 200.25 \mathrm{UM}, \mathrm{USA})$ for fatty acid compositions.

After setting the injector and detector temperature to $220^{\circ} \mathrm{C}$ and $280^{\circ} \mathrm{C}$ respectively, the oven temperature was kept at $140^{\circ} \mathrm{C}$ for 5 minutes. At $200^{\circ} \mathrm{C}$ at $4^{\circ} \mathrm{C} / \mathrm{min}$ and then at $220^{\circ} \mathrm{C}$ at $1{ }^{\circ} \mathrm{C} / \mathrm{min}$. The size of the samples was adjusted to $1 \mu \mathrm{l}$ and the carrier gas was run at 16psi, using a 1: 100 split ratio as separation. Two repetitive GC analyzes were performed to determine the fatty acids and the results obtained were expressed as the mean value in $\%$ of GC area and \pm standard deviation.

\section{Statistical analysis}

The statistical analysis of the obtained data was performed using the one-way analysis of variance (One-WayAnova) and the SPSS package program. In addition, correlation analysis, multiple regression analysis, whether there is any relation between dependent variables and independent variables, and the level, direction and significance levels of the existing relationship have also been tried to be determined by SPSS package program. The scatter graphs were also used for the visual expression of the analysis results. After applying variance analysis (ANOVA) to the obtained data, multiple comparison analysis was performed with $\mathrm{P}<0.05$ significance level.

\section{Findings and discussion}

The amounts of fatty acids detected in milk, blood, faeces and urine of cows in study are shown in Table 1 and the changes are given in Graph 1.

When Table 1 and Graph 1 are examined, it is seen that the animals have high levels of capric acid, lauric acid, myristic acid, palmitic acid, stearic acid, oleic acid and linoleic acid in the milk. In these fatty acids, palmitic acid is the most abundant in milk. Butyric acid is not present in milk, although it is in urine and in faeces.

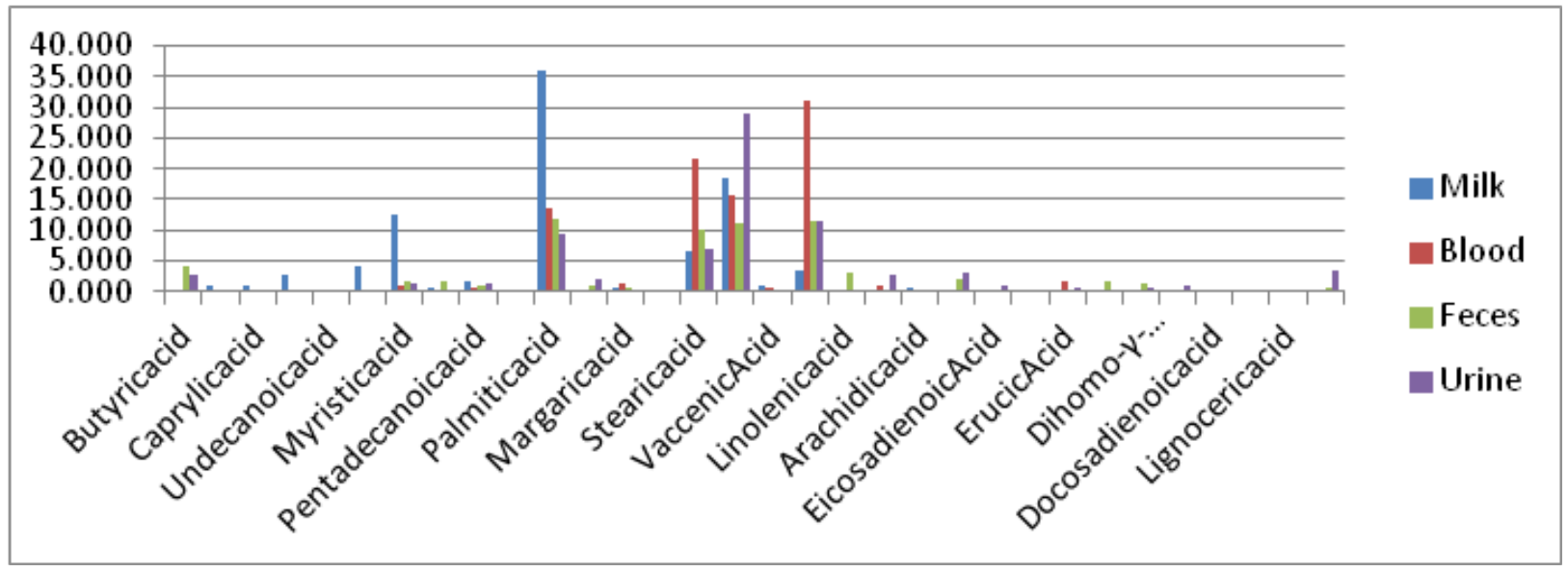

Graph I Comparison of fatty acids in milk, blood, feces and urine of cows. 
Table I Fatty acids and percentages detected in milk, blood, feces and urine of cows

\begin{tabular}{|c|c|c|c|c|}
\hline Name of Fatty Acids & $\begin{array}{l}\text { Percentage of fatty } \\
\text { acids in milk }\end{array}$ & $\begin{array}{l}\text { Percentage of fatty } \\
\text { acids in blood }\end{array}$ & $\begin{array}{l}\text { Percentage of fatty } \\
\text { acids in feces }\end{array}$ & $\begin{array}{l}\text { Percentage of fatty } \\
\text { acids in the urine }\end{array}$ \\
\hline Butyricacid & 0,00 & 0,00 & 4,25 & 2,70 \\
\hline Caproicacid & 0,86 & 0,08 & 0,30 & 0,34 \\
\hline Caprylicacid & 0,81 & 0,07 & 0,00 & 0,07 \\
\hline Capricacid & 2,75 & 0,16 & 0,00 & 0,00 \\
\hline Undecanoicacid & 0,11 & 0,00 & 0,00 & 0,00 \\
\hline Laurikacid & 3,97 & 0,26 & 0,21 & 0,00 \\
\hline Myristicacid & 12,56 & 1,13 & 1,68 & 1,46 \\
\hline Myristoleicacid & 0,54 & 0,33 & 1,59 & 0,00 \\
\hline Pentadecanoicacid & 1,51 & 0,49 & 1,00 & 1,15 \\
\hline Methylpentadecanoate & 0,21 & 0,30 & 0,43 & 0,00 \\
\hline Palmiticacid & 36,05 & 13,45 & 11,66 & 9,45 \\
\hline Palmitoleicacid & 0,36 & 0,32 & 0,91 & 2,05 \\
\hline Margaricacid & 0,61 & 1,22 & 0,49 & 0,14 \\
\hline Heptadecenoicacid & 0,07 & 0,09 & 0,00 & 0,00 \\
\hline Stearicacid & 6,69 & 21,64 & 10,07 & 6,79 \\
\hline Oleicacid & 18,33 & 15,75 & 11,14 & 28,92 \\
\hline VaccenicAcid & 0,87 & 0,48 & 0,00 & 0,00 \\
\hline Linoleicacid & 3,52 & 31,01 & 11,41 & 11,52 \\
\hline Linolenicacid & 0,06 & 0,34 & 3,07 & 0,22 \\
\hline Alpha LinolenicAcid & 0,24 & 0,96 & 0,36 & 2,74 \\
\hline Arachidicacid & 0,64 & 0,21 & 0,33 & 0,35 \\
\hline Eicosanoicacid & 0,09 & 0,17 & 2,10 & 3,07 \\
\hline EicosadienoicAcid & 0,06 & 0,09 & 0,00 & 1,12 \\
\hline Arachidonicacid & 0,06 & 0,16 & 0,33 & 0,00 \\
\hline ErucicAcid & 0,23 & 1,74 & 0,00 & 0,44 \\
\hline BehenicAcid & 0,04 & 0,00 & 1,82 & 0,14 \\
\hline Dihomo- $\gamma$-linolenicacid & 0,03 & 0,11 & 1,42 & 0,44 \\
\hline EicosapentaenoicAcid (EPA) & 0,02 & 0,15 & 0,00 & 1,07 \\
\hline Docosadienoicacid & 0,08 & 0,00 & 0,00 & 0,00 \\
\hline NervonicAcid & 0,06 & 0,00 & 0,00 & 0,00 \\
\hline Lignocericacid & 0,03 & 0,13 & 0,33 & 0,26 \\
\hline Docosahexaenoicacid & 0,05 & 0,08 & 0,54 & 3,58 \\
\hline
\end{tabular}

Blood palmitic acid, stearic acid, oleic acid and linoleic acid at high levels. There are no butyric acid, undecanoic acid, behenic acid, docosadienoic acid and nervonic acid, although linoleic acid is the highest among these fatty acids.

In the faeces the rates of butyric acid, palmitic acid, stearic acid, oleic acid, linoleic acid and linoleic acid are high.The highest ratio of fatty acids is palmitic acid, stearic acid, oleic acid and linoleic acid. ecause the percentages of these acids are very close to each other. There are no capric acid, caprylic acid, undecanoic acid, vaxenic acid, heptadecanoic acid, eicosyenoic acid, erucic acid, EPA, doosadienoic acid and nervonic acid in the faeces.

Palmitic acid, stearic acid, oleic acid, linoleic acid are high in the urine. Oleic acid is the fatty acid with the highest rate in the urine. There are no capric acid, undecanoic acid, lauric acid, myristoleic acid, methylpentadecanoate, heptadecanoic acid, vaksenic acid, arachidonic acid, doosadienoic acid and nervonic acid in the urine.

The ratio of $\Sigma$ SFA, $\Sigma$ MUFA and $\Sigma$ PUFA of fatty acids in milk, blood, feces and urine is given in Table 2 . 
Table $2 \Sigma$ SFA, $\Sigma$ MUFA and $\Sigma$ PUFA ratios of fatty acids in milk, blood, feces and urine

\begin{tabular}{|c|c|c|c|c|}
\hline \multirow{2}{*}{ Fatty Acids } & \multicolumn{4}{|c|}{ Percentage of fatty acids (\%) } \\
\hline & Milk & Blood & Feces & Urine \\
\hline C10:0 & 2,75 & 0,16 & 0,00 & 0,00 \\
\hline $\mathrm{C} 11: 0$ & 0,11 & 0,00 & 0,00 & 0,00 \\
\hline C12:0 & 3,97 & 0,26 & 0,21 & 0,00 \\
\hline C13:0 & 0,00 & 0,00 & 0,00 & 0,00 \\
\hline C14:0 & 0,54 & 0,33 & 1,59 & 0,00 \\
\hline $\mathrm{C} 15: 0$ & 1,51 & 0,49 & 1,00 & 1,15 \\
\hline $\mathrm{C} 16: 0$ & 36,05 & 13,45 & 11,66 & 9,45 \\
\hline $\mathrm{C} 17: 0$ & 0,61 & 1,22 & 0,49 & 0,14 \\
\hline C18:0 & 6,69 & 21,64 & 10,07 & 6,79 \\
\hline $\mathrm{C} 20: 0$ & 0,64 & 0,21 & 0,33 & 0,35 \\
\hline $\mathrm{C} 21: 0$ & 0,00 & 0,00 & 0,00 & 0,00 \\
\hline $\mathrm{C} 22: 0$ & 0,04 & 0,00 & 1,82 & 0,14 \\
\hline $\mathrm{C} 23: 0$ & 0,00 & 0,00 & 0,00 & 0,00 \\
\hline $\mathrm{C} 24: 0$ & 0,03 & 0,13 & 0,33 & 0,26 \\
\hline$\sum$ SFA & 52,94 & 37,89 & 27,5 & 18,28 \\
\hline $\mathrm{C} 14: 1$ & 0,54 & 0,33 & 1,59 & 0,00 \\
\hline C15:1 & 0,21 & 0,30 & 0,43 & 0,00 \\
\hline C16:1 & 0,36 & 0,32 & 0,91 & 2,05 \\
\hline $\mathrm{C} 17: 1$ & 0,07 & 0,09 & 0,00 & 0,00 \\
\hline $\mathrm{C} 18: \ln 7 \mathrm{c}$ & 0,87 & 0,48 & 0,00 & 0,00 \\
\hline C18:1n9c & 18,33 & 15,75 & 11,14 & 28,92 \\
\hline $\mathrm{C} 20: 1$ & 0,09 & 0,17 & 2,10 & 3,07 \\
\hline$\sum$ MUFA & 20,47 & 17,44 & 16,17 & 34,04 \\
\hline $\mathrm{C} 18: 2 \mathrm{n} 6$ & 3,52 & 31,01 & 11,41 & 11,52 \\
\hline $\mathrm{C} 18: 3 n 6$ & 0,06 & 0,34 & 3,07 & 0,22 \\
\hline $\mathrm{C} 18: 3 \mathrm{n} 3$ & 0,24 & 0,96 & 0,36 & 2,74 \\
\hline $\mathrm{C} 20: 2$ cis & 0,06 & 0,09 & 0,00 & 1,12 \\
\hline $\mathrm{C} 20: 3$ n 6 & 0,03 & 0,11 & 1,42 & 0,44 \\
\hline C20:4 n6 & 0,06 & 0,16 & 0,33 & 0,00 \\
\hline $\mathrm{C} 20: 5 \mathrm{n} 3$ & 0,02 & 0,15 & 0,00 & 1,07 \\
\hline $\mathrm{C} 22: 6$ n3 & 0,05 & 0,08 & 0,54 & 3,58 \\
\hline$\sum$ PUFA & 4,04 & 32,9 & 17,13 & 20,69 \\
\hline MUFA/SFA & 0.386 & 0,460 & 0,588 & 1,862 \\
\hline PUFA/SFA & 0,076 & 0,868 & 0,622 & 1,131 \\
\hline PUFA/MUFA & 0,197 & 1,886 & 1,059 & 0,607 \\
\hline$\sum \mathrm{n} 6$ & 3,67 & 31,62 & 16,23 & 12,18 \\
\hline$\sum \mathrm{n} 3$ & 0,31 & 1,19 & 0,9 & 7,39 \\
\hline n6/n3 & 11,83 & 26,57 & 18,03 & 1,64 \\
\hline
\end{tabular}

Kovac et al. ${ }^{15}$ analyzed the fatty acids found in the blood of animals and found the results as $\Sigma \mathrm{SFA}=42,67, \Sigma \mathrm{MUFA}=16,86, \Sigma \mathrm{n} 6=33,97$ and $\Sigma \mathrm{n} 3=4,50$. When the results of the analysis are compared with those of Table 2, $\Sigma$ SFA, $\Sigma \mathrm{n} 6$ and $\Sigma \mathrm{n} 3$ values are high and $\Sigma$ MUFA values are low.

In the above-mentioned studies, Baer ${ }^{16}$ said that the reason for the variation in fatty acid ratios is due to factors such as lactation, seasonal changes, nutrition, genetic variation, and changes in the energy state of the cattle such as cattle somatotrophy.

The result of the correlation analysis to determine the relationship between fatty acid contents detected in milk, feces, blood and urine specimens is given in Table 3. As a result of the correlation analysis, statistically significant $(p<0.01)$ relation between milk, feces, blood and urine fatty acids was found (Table 3 ).

\begin{tabular}{|c|c|c|c|}
\hline & $\mathbf{n}$ & $\mathbf{R}$ & $\mathbf{P}$ \\
\hline Milk-blood & 32 & $0,487 * *$ & 0,005 \\
\hline Milk-feces & 32 & $0,706^{* *}$ & 0,000 \\
\hline Milk-urine & 32 & $0,607 * *$ & 0,000 \\
\hline Blood-feces & 32 & $0,899 * *$ & 0,000 \\
\hline Blood-urine & 32 & $0,701 * *$ & 0,000 \\
\hline Feces-urine & 32 & $0,804 * *$ & 0,000 \\
\hline
\end{tabular}

As a result of the correlation analysis to determine the relationship between fatty acid contents detected in milk, feces, blood and urine samples. There was a moderate correlation between milk and blood, and this correlation was statistically significant $(\mathrm{p}<0.01)(\mathrm{r} 0.487$, $\mathrm{p}=0.005$ ). There is a high level of correlation between milk and feces and this relationship is statistically significant $(\mathrm{p}<0.01) \quad(\mathrm{r}=0.706$, $\mathrm{p}=0.000$ ). It can be said that there is a moderate relationship between milk and urine, and this relationship is statistically significant $(\mathrm{r}=0.607$, $\mathrm{p}=0.000$ ). There is also a high correlation between blood and feces and blood and urine, and this relationship is statistically significant $(\mathrm{p}<0.01)(\mathrm{r}=0.899, \mathrm{p}=0.000$ and $\mathrm{r}=0.701, \mathrm{p}=0.000$, respectively $)$.It was also found that there was a high level of correlation between faeces and urine $(\mathrm{r}=0.804, \mathrm{p}=0.000)$ and statistically significant $(\mathrm{p}<0.01)$.

Table 2 shows that there is a positive correlation between levels of fatty acids detected in milk, feces, blood and urine.

The results of multiple regression analysis to determine the level of relationships between levels of fatty acids detected in milk, feces, blood, and urine are given in the table.

According to the table above, the ANOVA test was significant. The $P$ value is $0,000(p<0.01)$. That is, the regression model is meaningful as a whole.

The results of the multiple linear regression analysis to determine the relationship between fatty acid contents detected in milk, faeces, blood, and urine specimens are shown in Table 4.

When we look at the values in the table, the $\mathrm{R}^{2}$ value is calculated as 0,612 and the corrected $\mathrm{R}^{2}=0,569$ in the dependent variable column and it is determined that there is a moderate correlation in the positive direction. The feces, urine and blood, which are independent variables, can account for $57 \%$ of the dependent variable, milk. The dependent 
variable kanda, corrected $\mathrm{R}^{2}=0.835$, indicates that there is a high level of correlation in the positive direction and that the independent variables milk, feces, urine can accommodate $83 \%$ of the change in the dependent variable.

When the independent variable is feces, corrected $R^{2}=0.909$, it is seen that there is a very high level of correlation in the positive direction and that the independent variables milk, blood and urine can cover $91 \%$ of the change in the faeces. Adjusted $\mathrm{R}^{2}=0.613$ in the dependent variable, urine is found to be moderate and corresponds to $61 \%$ of the independent variables milk, blood, feces.

The coefficients and significance values of the regression model obtained as a result of the analysis applied to the fatty acids are given in Table 5. When dependent variable milk is selected, the coefficient of the constant term is calculated as -0.697 and the value of $p$ is specified as 0,504 . In this case, the fixed term does not make sense. The coefficient of the regression model of the blood is $-0,765$. The significance level of the $T$ test was calculated as $p=0,010$ and $\mathrm{p}<0,05$, which is statistically significant. However, as can be seen, the conversion rates of the fatty acids in the blood are inversely correlated with milk. Because the regression model coefficient is negative. Outcome regression model coefficient was calculated as 2,696 and $\mathrm{p}=0.00$ and milk and feces were statistically significant $(\mathrm{p}<0,05)$.

When the blood was selected as the dependent variable, the blood regression model coefficients $\mathrm{B}=-0,292$ and $\mathrm{p}=0,008$ were found and the relationship between blood and milk was found significant. $(\mathrm{P}<0.05)$. Since $\mathrm{B}$ carries a negative value, the fatty acid change rates in the milk have an inversely proportional relationship with blood. The relation of blood to stool was also significant $(p=0,000, p<0,05)$. Another way to estimate the proportion of blood fatty acids, which are dependent variables, is that fatty acids found in milk and feces contribute significantly to the model.

Table 4 Results of multiple regression analysis

\begin{tabular}{lllllll}
\hline The dependent variable & $\mathbf{R}$ & $\mathbf{R}^{\mathbf{2}}$ & Adjusted $\mathbf{R}^{\mathbf{2}}$ & $\mathbf{d f}$ & $\mathbf{F}$ & $\mathbf{p}$ \\
\hline Milk &, 782 &, 612 &, 569 & 3 & 14,205 & 0,000 \\
Blood &, 923 &, 851 &, 835 & 3 & 53,470 & 0,000 \\
Feces &, 958 &, 918 &, 909 & 3 & 104,208 & 0,000 \\
Urine &, 806 &, 650 &, 613 & 3 & 17,340 & 0,000
\end{tabular}

Table 5 Coefficients and significance value of regression model

\begin{tabular}{|c|c|c|c|c|c|c|c|c|c|c|c|}
\hline $\begin{array}{l}\text { The dependent } \\
\text { variable- Milk }\end{array}$ & B & $\mathbf{p}$ & $\begin{array}{l}\text { The dependent } \\
\text { variable- Blood }\end{array}$ & B & $\mathbf{p}$ & $\begin{array}{l}\text { The dependent } \\
\text { variable Urine }\end{array}$ & B & $\mathbf{p}$ & $\begin{array}{l}\text { The dependent } \\
\text { variable Feces }\end{array}$ & B & $\mathbf{P}$ \\
\hline Fixed term &,- 697 &, 504 & Fixed term &,- 846 &, 167 & Fixed term &,- 145 & 844 & Fixed term & ,445 &, 046 \\
\hline Blood &,- 765 &, 010 & Milk &,- 292 & ,008 & Milk &, 044 & ,751 & Milk &, 142 &, 000 \\
\hline Feces & 2,696 &, 000 & Feces & 2,259 &, 000 & Feces & 1,277 & ,029 & Blood & ,312 &, 000 \\
\hline Urine &, 082 &, 757 & Urine &,- 037 & ,816 & Blood &,- 053 & ,816 & Urine &, 125 & 029 \\
\hline
\end{tabular}

When the feces was selected as the dependent variable, the regression model coefficient of feces was $\mathrm{B}=0,445$ and $\mathrm{p}<0,05$ in $\mathrm{p}$, milk, blood and urine, so the relation of feces with milk, blood and urine was found significant. It has been determined that the change in fatty acids in milk, blood, and urine did not significantly predict fatty acids in the feces.

When the dependent variable urine was selected, the urine regression model coefficient $\mathrm{B}=-0,144$ was found and it was found that the urine had an inverse relationship with the feces $(\mathrm{P}<0.05)$. The table indicates that changes in the fecal fatty acids in the stool will contribute significantly to the change in the fecal matter due to the reflection of the urine in the reverse direction.

To meet the energy needs of animals with a negative energy balance, adipose tissues act and increase plasma non-unesterified fatty acids (NEFA) concentrations due to lipolysis. ${ }^{17}$ Increases in feeding (energy) uptake increase the need for precursors (acetate, butyrate) for milk oils (C: 6-C: 16), which are mainly expressed in the mammary gland. ${ }^{18}$ According to this information, Miettinen and Huhtanen, in their study of 1989, found that there is an increasing positive correlation between chain length of fatty acids up to chain length $\mathrm{C} 16$ and ME-balance in milk. ${ }^{19} \mathrm{~A}$ high positive correlation between C16: 0 (palmitic acid) and ME-balance was associated with the expression of a large proportion of palmitic acid in the mammary glands. By dropping the metabolic energy, body oils are actuated

and the proportions of palmitoleic and $\mathrm{C} 18$ fatty acids in the milk increase. The reason for this is that the triglycerides of body fat stores in cattle are mostly fatty acids in the form of palmitic, stearic and oleic acids. They point out that palmitic acid is partly due to desaturation activity in the mammary gland, which converts palmitoleic acid and stearic acid to oleic acid, and that these results may be a good indicator of the fatty acid composition of milk fat in the dairy cows.

Kamila et al. ${ }^{20}$ noted that the high presence of unesterified fatty acids (NEFA) is a sign of the consumption of lipid reserves to balance the disproportion between the energy provided by feed ration and the energy required for milk production, and is associated with a higher incidence of metabolic disease later in life. Geishauser et al. ${ }^{21}$ reported that $\beta$-hydroxybutyric acid (BHBA) concentrations in the first week after birth may be indicative of subclinical ketosis. Jorjong et al. ${ }^{22}$ reported that the increase in the concentration of C18: 1 cis-9 (oleic acid = milk fat) in the second week of lactation may be a symptom that can be detected early for the risk of developing high blood levels of NEFA, and based on this knowledge, Kamila et al..$^{20}$ noted that the increase in oleic acid found in milk during early stages of lactation in high yielding cows could be applied as a biomarker for the early detection of NEFA and BHBA at high levels of calm.

Stefańska et al. ${ }^{23}$ conducted this study to investigate the effect of ruminal fluid $\mathrm{pH}$ on blood, urine, faeces and milk biochemical indices and to determine which may be useful for the diagnosis of 
subacute ruminal acidosis. As a result of the study, they reported that ruminal fluid $\mathrm{pH}$ showed a positive correlation $(\mathrm{p} \leq 0.01)$ with the stamina concentrations of SFA and blood $\mathrm{pH}$ values. Reduction in the absorption rate of ruminal essential fatty acids in animals with subacute renalacidosis causes ruminal $\mathrm{pH}$ to fall for two reasons: Ruminal essential fatty acids are the accumulation and decrease of bicarbonate input and $\mathrm{pH}$ from the blood stream. Decrease in the $\mathrm{pH}$ of the ruminal fluid was found to be the resultant increase in IGF-I, free fatty acid levels, and decrease in rectal temperature and blood $\mathrm{pH}$ values. These data indicate that these values may be used as indicators in physiological changes and may help in the diagnosis of subacute ruminal acidosis syndrome when serial measurements are made.

The energy metabolism of dairy cows during the transition period is closely related to lipid metabolism. The best indicator of negative energy balance and the degree of mobility of lipids at transition from body fat reserves is due to increased free fatty acid (SFA) concentrations. In this period there is an increase in blood SFA concentrations bound to albumin and carried to the liver. ${ }^{24,25}$ Djokovic et al. ${ }^{26}$ reported significantly higher concentrations of free fatty acids in the blood of ketosis cows $(\mathrm{p}<0.01)$ compared to healthy cows before and after calving. There was a significant positive correlation $(\mathrm{r}=0.51$; $\mathrm{p}<0.05$ ) between the free fatty acids in the liver and the lipid content in the liver and a negative correlation $(r=-0.64 ; \mathrm{p}<0.05)$ between free fatty acids and triacylglycerol concentrations in the ketosis cows stated.When they compared the results of the study with the results of other authors, ${ }^{24}$ they showed that the increase in the concentration of free fatty acids in the blood clearly showed that the lipid content in the liver cells was increased.Liver lesions that appear as a consequence of lipomobilization are usually observed in highly productive cows at the first stage of lactation. The development of these hepatic lesions increases the likelihood of diseases such as ketosis, mastitis, metritis, hypocalcemia, abomasum depression and placenta retention. ${ }^{27}$

In this study, the ratio of $\Sigma$ SFA was found high in milk, feces and stool as shown in Table 2. As a result of the regression analysis made in Table 4, it is found that the dependent variable $\mathrm{R}^{2}$, which is corrected $\mathrm{R}^{2}=0.835$, has a high level of correlation in the positive direction and that the independent variables milk, feces, urine can meet $83 \%$ of the variation in the dependent variable. According to the regression analysis (Table 5), the relation of feces with milk, blood and urine was significant and it was found that the change of fatty acids in milk, blood and urine did not significantly predict fatty acids in feces. ${ }^{28}$

\section{Results}

The various fatty acids found in the blood circulation, cells and tissues of animals are a rich source of energy for animals and important components of events occurring in the cell. It has been determined that there is a significant relationship between fecal matter, milk, blood and urine fat contents in this study which is carried out to investigate the correlation between fecal matter, urine, milk and blood fatty acid contents in holstein cows and multiple regression analysis. When the fatty acid compositions of milk, feces urine and blood, and SFA, $\Sigma$ MUFA and $\Sigma$ PUFA ratios were examined, it was found that the ratio of $\Sigma$ SFA to milk, blood and faeces was high and $\Sigma$ MUFA ratio was high in urine. As a result of the correlation analysis, statistically significant $(\mathrm{p}<0.01)$ relationship between milk, feces, blood and urine fatty acids was found.
There are studies that report that the fatty acid composition of milk fat may be a good indicator of energy status in dairy cows. It is understood that the sample showing close similarity and correlation with blood fatty acids from blood, feces and urine can be used at a high level in the prediction of negative energy according to the regression model.

\section{Acknowledgments}

None.

\section{Conflicts of interest}

Author declares there is no conflict of interest.

\section{References}

1. Bayizit AA. The importance of unsaturated fatty acids in terms of nutrition and health. J Food \& Feed Science-Technology. 2003;3:2831.

2. Lee KN, Kritchevsky D, Pariza MW. Conjugated linoleic acid and atherosclerosis in rabbits. Atherosclerosis. 1994;108(1):19-25.

3. Von Schacky C. n-3 Fatty acids and the prevention of coronary atherosclerosis. American J Clinical Nutrition. 2000;71(1):224-227.

4. James MJ, Gibson RA, Clevland LG. Dietary polyunsaturated fatty acids and inflammatory mediator production. American $J$ Clinical Nutrition. 2000;71(1):343-348.

5. Yamada T, Strong JP, Ishii T, et al. Atherosclerosis and $\omega-3$ fatty acids in the populations of a fishing village and a farming village in Japan. Atherosclerosis. 2000;153(2):469-481.

6. Tagang A, Ishaku PK, Abdullah A. Volatile fatty acids: production in ruminants and the role of monocarboxylate transporters. A review. Afr J Biotechnol. 2010;9(38):6229-6232.

7. Burr GO, Burr MM. On the nature and role of the fatty acids essential in nutrition. $J$ Biol Chem. 1930;86:587-621.

8. Santos JELF. Greco M Garcia, Thatcher WW, et al. The role of specific fatty acids on dairy cattle performance and fertility. Florida Ruminant Nutrition Symposium. 2013.

9. Drackley JK. Biology of dairycowsduringthetransitionperiod: The final frontier? J Dairy Sci. 1999;82(11):2259-2273.

10. Van der Drift SGA, Houweling M, Schonewille JT, et al. Protein and fat mobilization and associations with serum $\beta$ hydroxybutyrate concentrations in dairy cows. J Dairy Sci. 2012;95:4911-4920.

11. Sankar R, Archunan G. Identification of putativepheromones in bovine (Bos taurus) faeces in relationtoestrusdetection. Anim Reprod Sci. 2008;103(1-2):149-153.

12. Klemm WR, Rivard GF, and Clement BA. Blood acetaldehyde fluctuates markedly during bovine estrous cycle. Anim Reprod Sci. 1994;35(1-2):9-26.

13. Bligh EG, Dyer WJ. Arapid method of total lipid extraction and purification. Can J Biochem Physiol. 1959;37(8):911-917.

14. Kumar RK, Archunan G, Jeyaraman R, et al. Chemical characterization of bovine urine with special reference to oestrus. Vet Res Comm. 2000;24(7):445-454.

15. Kovac G, Seidel H, Mudron P, et al. Blood plasma fatty acid concentrations in cattle during the transitional feeding period (winter -summer). Actavet Brno. 1996;65:193-199. 
16. Baer RJ. Alteration of the Fatty Acid Content of Milk Fat. $J$ Food Protection. 1991;54(5):383-386.

17. Bell AW. Regulation of organic nutrient metabolism during transition from late pregnancy to early lactation. J Anim Sci. 1995;73(9):28042819.

18. Moore J, Christie WW. Lipidmetabolism in the mammary gland of ruminant animals. Lipidmetabolism in ruminant animials. Oxford: Pergamon Press; 1981:227-278.

19. Miettinen H, Huhtanen P. The concentrations of blood metabolites and the relations between blood parameters, fatty acid composition of milk and estimated me-balance in dairy cows given grass silage ad libitum with five different carbohydrate supplements. Acta Agriculturae Scandinavica. 1989;39(3):319-330.

20. Kamila P, Paweł S, Beata K, et al. Oleicacid as a biomarker for early diagnosis of elevated blood levels of non-esterified fattyacids and $\beta$-hydroxybutyricacid in the early stages of lactation in highyielding Polish Holstein cows. Animal Science Papersand Reportsvol. 2017;35(4):387-396.

21. Geishauser T, Leslie K, Kelton D, et al. Monitoringforsubclinicalketosis in dairyherds. Compendium on Continuing Education for the PractisingVeterinarian. 2001;23:65-71.

22. Jorjong S, Van Knegsel ATM, Verwaeren J, et al. Milk fatty acids as possible biomarkers to early diagnose elevated concentrations of blood plasma non esterified fatty acids in dairy cows. $J$ Dairy Sci. 2014;97(11):7054-7064.

23. Stefańska, B, Pruszyńska-Oszmałek E, Szczepankiewicz D, et al. Relationship between $\mathrm{pH}$ of ruminal fluid during subacute ruminal acid osis and physiological response of the Polish Holstein-Friesiand airy cows. Pol J Vet Sci. 2017;20(3):551-558.

24. Reist M, Erdın D, VonEuw D, et al. Estimation of energybalance at the individual and herdlevel using blood and milk traits in high-yielding dairy cows. J Dairy Sci. 2002;85(12):3314-3327.

25. Overton TR, McArt JAA, Nydam DV. A 100-Year Review: Metabolic health indicators and management of dairy cattle. J Dairy Sci. 2017;100(12):10398-10417.

26. Djoković R, Šamanc H, Jovanović M, et al. blood concentrations of thyroid hormonesand lipids and content of lipids in theliver in dairy cows in transitional period. Acta Vet Brno. 2007;76(4):525-532.

27. Ametaj BN. A new understanding of the causes of fatty liver in dairy cows. Adv Dairy Technol. 2005;17:97-112.

28. Didara M, Šperanda M, Domaćinović $M$, et al. Plasmaandmilkfattyacidcomposition as a responsetodietary n-3 fatty acids and selenium in periparturient Holsteincows. Mljekarstvo. 2017;67(2):123-129 